\title{
BMJ Global Health Unraveling PBF effects beyond impact evaluation: results from a qualitative study in Cameroon
}

\author{
Manuela De Allegri, ${ }^{1}$ Maria Paola Bertone ${ }^{2}$ Shannon McMahon, ${ }^{1}$ \\ Idrissou Mounpe Chare, ${ }^{3}$ Paul Jacob Robyn ${ }^{4}$
}

To cite: De Allegri M,

Bertone MP, McMahon S, et al. Unraveling PBF effects beyond impact evaluation: results from a qualitative study in Cameroon. BMJ Glob Health 2018;3:e000693. doi:10.1136/ bmjgh-2017-000693

Handling editor Seye Abimbola

- Additional material is published online only. To view please visit the journal online (http://dx.doi.org/10.1136/ bmjgh-2017-000693).

MDA and MPB contributed equally.

Received 21 December 2017 Revised 28 January 2018 Accepted 14 February 2018

Check for updates

${ }^{1}$ Institute of Public Health, Medical Faculty, Heidelberg University, Heidelberg, Germany ${ }^{2}$ Institute for Global Health and Development, Queen Margaret University, Edinburgh, UK ${ }^{3}$ Department of Sociology, University of Yaoundé I, Yaoundé, Cameroon

${ }^{4}$ Health, Nutrition, and Population Unit, The World Bank, Washington, District of Columbia, USA

\section{Correspondence to}

Dr Manuela De Allegri, Institute of Public Health;

manuela.de.allegri@urz.uniheidelberg.de

\section{ABSTRACT}

Introduction Performance-based financing (PBF) has acquired increased prominence as a means of reforming health system purchasing structures in low-income and middle-income countries. A number of impact evaluations have noted that PBF often produces mixed and heterogeneous effects. Still, little systematic effort has been channelled towards understanding what causes such heterogeneity, including looking more closely at implementation processes.

Methods Our qualitative study aimed at closing this gap in knowledge by attempting to unpack the mixed and heterogeneous effects detected by the PBF impact evaluation in Cameroon to inform further implementation as the country scales up the PBF approach. We collected data at all levels of the health system (national, district, facility) and at the community level, using a mixture of in-depth interviews and focus group discussions. We combined deductive and inductive analytical techniques and applied analyst triangulation.

Results Our findings indicate that heterogeneity in effects across facilities could be explained by preexisting infrastructural weaknesses coupled with rigid administrative processes and implementation challenges, while heterogeneity across indicators could be explained by providers' practices, privileging services where demand-side barriers were less substantive.

Conclusion In light of the country's commitment to scaling up PBF, it follows that substantial efforts (particularly entrusting facilities with more financial autonomy) should be made to overcome infrastructural and demand-side barriers and to smooth implementation processes, thus, enabling healthcare providers to use PBF resources and management models to a fuller potential.

\section{BACKGROUND}

Performance-based financing (PBF) is a health financing reform that entails a shift in purchasing modalities by introducing a transfer of resources to providers based on a contract, which defines a bonus payment according to a fee-for-service schedule for a selected list of services, conditional on a measure of quality. ${ }^{1}$ In the last decade, PBF programs have proliferated across many low-income and middle-income countries,

\section{Key questions}

What is already known about this topic?

- A number of impact evaluations of performancebased financing (PBF) programs have pointed to the fact that PBF often produces mixed and heterogeneous effects.

- Relatively little scientific effort has sought to understand how implementation processes affect the efficacy of an intervention and can explain the observed outcomes.

\section{What are the new findings?}

- This study represents one of the first attempts to use qualitative research to explicitly explain heterogeneity in the effects detected by the quantitative impact evaluation of a PBF program.

- Heterogeneity in the outcomes produced by PBF could be attributed both to health systems factors hampering the potential of the intervention to achieve its set objectives and to the ways individual healthcare providers responded to the intervention.

\section{Recommendations for policy}

- Based on our findings, we propose three, broad recommendations for policymakers: (1) pay closer attention to implementation challenges and bottlenecks linked to pre-existing health system structures, (2) consider demand-side barriers and monitor the potential for PBF to be effectively pro-poor and (3) invest in measures to ensure greater equity across all districts and facilities.

particularly in sub-Saharan Africa. ${ }^{1}$ Empirical research has accompanied this growth and focused primarily on quantitatively assessing PBF's impact on: health outputs and outcomes, patient satisfaction, and the quality of service delivery. ${ }^{2-8}$ Some of these studies have shown a positive association between $\mathrm{PBF}$ and health service coverage or quality, but most have uncovered mixed results. Recently, as part of an effort to understand these mixed results, a number of qualitative and mixed-methods studies have emerged exploring PBF's implementation processes ${ }^{910}$; 
providers' and communities' perceptions of $\mathrm{PBF}^{11}{ }^{12}$; providers' incentives, motivation and performance ${ }^{13-15}$ and implementation perspectives among national stakeholders ${ }^{16}$ or in a cross-country analyses. ${ }^{17}$

Gaps remain in understanding why and through which mechanisms PBF has (or has not) attained expected results or has achieved mixed or heterogeneous results, that is, positive results on some indicators or for some facilities and areas, yet no impact on or in others. PBF proponents and detractors are grappling with questions about whether the reform's successes or setbacks lie in design or rather in implementation; whether key assumptions inherent to PBF (ie, linking payments and results, independently verifying results, fostering managerial autonomy of facilities and so on) are playing out as expected; how contextual factors contribute to outcomes and whether adjustments could be made to improve programmes. ${ }^{18} 19$

In this paper, we present results of a qualitative study that seeks to address a gap in the literature by looking specifically at experiences of PBF in Cameroon. Building on findings from a quantitative impact evaluation, ${ }^{8}$ this study investigates factors that may explain heterogeneity in performance across PBF indicators and facilities. The study also explores how providers, managers and communities perceived the design and rollout of PBF. As several low-income and middle-income countries move to scale with PBF, evidence and lessons learnt herein will be useful to inform implementation well beyond our study setting.

\section{METHODS}

\section{Study setting}

In Cameroon, socioeconomic conditions have deteriorated in recent decades and the relative rank of the country fell from the 97th place in the 1980 Human Development Index to $153 \mathrm{rd}$ in $2014 .^{20}$ Several key millennium development goals were not achieved. Under-five mortality, maternal mortality and general adult mortality (15-60 years) were listed, respectively, at 88/1000, 508/100 000 and $403 / 1000$ in $2015^{21}$; skilled birth attendance has settled at around $60 \%-65 \%$ since the $1990 \mathrm{~s},{ }^{22}$ and HIV prevalence (4.5\% in 2015) continues to be substantially higher than in neighbouring countries. ${ }^{23}$

With the objective of increasing utilisation and improving the quality of health service delivery, the Ministry of Health (with financial support from the World Bank) in 2011 launched a PBF pilot in the country's Littoral region, followed by a scale-up in 2012 to NorthWest, South-West and East regions, covering approximately 500 public, private and faith-based facilities (including primary and secondary facilities) across the four regions. ${ }^{24} 25$ The introduction of PBF was facilitated by a shift in political discourse favouring the implementation of more accountable health financing purchasing structures. ${ }^{25}$ Per the design, PBF bonuses were awarded for a list of services with a focus on maternal and childcare (see online Supplementary additional file 1). Bonuses were adjusted for quality of service delivery as determined based on a quality checklist. PBF payments were further adjusted adding an 'equity bonus' (a percentage of the basic PBF bonus, which varied between regions) to address contextual differences (such as remoteness, rural location or difficulty in access), which could affect service provision. Furthermore, facilities were to provide free services to the very poor identified in the communities and would receive a higher bonus payment from the PBF programme for services provided to the very poor to account for forgone user fees. PBF facilities filled in a monthly activity report, later verified by the 'fundholding agencies' in collaboration with District Health Management teams, based on which payment was made monthly. PBF bonuses were paid to facilities, with a proportion allocated to health workers (shared using an 'indice tool') and the rest, alongside other incomes from user fees and/or budget allocations, used to cover facility expenditures (running costs, small investments, etc) as decided autonomously and outlined in a quarterly business plan prepared jointly by the facility staff. ${ }^{26}$

An impact evaluation (IE) was carried out between mid-2012 and mid-2015 in 14 of 22 districts across three of the regions (excluding Littoral). Under the IE, all facilities were randomised to receive $\mathrm{PBF}$ or one of three alternative control interventions, which provided varied levels of financial support and supervision not conditional on performance. ${ }^{8}$

\section{Study design}

We engaged in an explanatory-exploratory cross-sectional qualitative study, ${ }^{27}$ which sought explanations for patterns observed in the quantitative IE (explanatory), but also allowed an open investigation into the way $\mathrm{PBF}$ was experienced across a range of stakeholders (exploratory). During the qualitative study's preparation, quantitative results as well as emerging interpretations and possible directions for qualitative research were discussed in depth with stakeholders in Yaoundé. Based on these discussions, the team finalised the study design, sampling, data collection strategy and tools and identified key themes to be explored qualitatively.

As highlighted earlier, preliminary results from the quantitative IE informed our qualitative work. Similar to other contexts, the IE in Cameroon showed that PBF produced overall positive changes in service coverage for some indicators (eg, maternal and child immunisation, family planning and HIV testing), but not for others (eg, antenatal care, assisted deliveries and child curative consultations) and recognised a limited capacity to reach the very poor. Looking at quality of care, the IE showed that PBF improved the availability of essential inputs and equipment, but not service delivery processes, in spite of an increased presence of qualified health workers and an increased patient satisfaction. ${ }^{8}$ The programme also induced heterogeneity in impact across and within districts, with some facilities performing better than others. 


\section{Data collection}

The study team conducted in-depth interviews (IDIs) and focus group discussions (FGDs) in order to capture perspectives on both the supply (providers and managers) and demand side (service users) and to include respondents across health system levels (communities, facilities, districts, regional and central levels). Table 1 illustrates the sample, data collection instrument and themes addressed in each set of interviews. In each region, we interviewed health workers in three purposively selected primary facilities (a high performer, a delayed performer and a low performer) and in one secondary facility to ensure representativeness across districts and across public and non-public facilities. District medical officers (DMOs) were interviewed in the same districts and women (service users) in the catchment areas of the same sampled facilities.
We completed data collection between December 2016 and January 2017 with support from trained research assistants in collaboration with Centre d'Etudes et de Recherches Appliquées en Sciences Sociales (CERASS), using semi-structured interview guides, either in English or French depending on the region.

\section{Data analysis}

FGDs and IDIs were recorded, verbatim transcribed in the original language (either French or English)and coded without further translation. Coding was performed in the original language of the interview. French quotes included in this paper have been translated, while those in English are reported verbatim with no adjustment. Coding of the transcripts followed a thematic approach, using a mixture of deductive and inductive coding techniques, which is aligned with the explanatory-exploratory

Table 1 Summary of respondents by level, type, number and instrument used

\begin{tabular}{|c|c|c|c|}
\hline Level & Number and type of respondents & $\begin{array}{l}\text { Instrument } \\
\text { type }\end{array}$ & $\begin{array}{l}\text { Description of data collected and topics } \\
\text { covered }\end{array}$ \\
\hline $\begin{array}{l}\text { National and } \\
\text { Regional }\end{array}$ & $\begin{array}{l}\text { Ministry of Health officials: five } \\
\text { Regional delegates: three } \\
\text { Fund-holding agency personnel: three } \\
\text { Total=11 }\end{array}$ & IDI & $\begin{array}{l}\text { Implementation challenges and solutions } \\
\text { devised } \\
\text { Role of PBF in shifting operating processes } \\
\text { within the health system } \\
\text { PBF and facility autonomy } \\
\text { Targeting of the very poor - knowledge, } \\
\text { applications, challenges }\end{array}$ \\
\hline District & $\begin{array}{l}\text { District Medical Officers (DMOs) } \rightarrow \\
\text { three in each region } \\
\text { Total }=9\end{array}$ & IDI & $\begin{array}{l}\text { Changes in work schedule induced by PBF } \\
\text { PBF ability to produce change in service } \\
\text { coverage } \\
\text { PBF and facility autonomy } \\
\text { Mitigation strategies for challenges induced by } \\
\text { PBF implementation } \\
\text { PBF and health worker retention } \\
\text { Targeting of the very poor-knowledge, } \\
\text { applications, challenges }\end{array}$ \\
\hline Facility & $\begin{array}{l}\text { Hospital-based providers: one hospital } \\
\text { per region } \rightarrow \text { three staff per hospital } \\
\text { (family planning, maternity ward, head } \\
\text { of facility) (total nine) } \\
\text { Health centre-based providers: three } \\
\text { health centres per region } \rightarrow \text { two staff } \\
\text { per health centre (family planning, } \\
\text { maternal and child services) (total 18) } \\
\text { Total=27 }\end{array}$ & IDI & $\begin{array}{l}\text { Changes in work schedule induced by PBF } \\
\text { PBF ability to produce change in service } \\
\text { provision } \\
\text { PBF and facility autonomy } \\
\text { Mitigation strategies for challenges induced by } \\
\text { PBF implementation } \\
\text { Satisfaction with operational aspects of PBF } \\
\text { implementation } \\
\text { Mitigation strategies for challenges induced by } \\
\text { PBF implementation }\end{array}$ \\
\hline Community & $\begin{array}{l}\text { Three FGDs per region with female } \\
\text { patients and service users } \\
\text { Total=9 } \\
\text { Three IDIs per region with women who } \\
\text { delivered at home (total nine) } \\
\text { Five IDIs per region with women who } \\
\text { use/do not use FP methods (total 15) } \\
\text { Total=24 }\end{array}$ & IDI and FGD & $\begin{array}{l}\text { Knowledge, beliefs and practices on specific } \\
\text { illnesses/services } \\
\text { PBF and care-seeking pathways } \\
\text { Community PBF engagement } \\
\text { PBF and access to care for the very poor }\end{array}$ \\
\hline Overall totals & $\begin{array}{l}\text { IDIs }=71 \\
\text { FGDs }=9\end{array}$ & & \\
\hline
\end{tabular}

FGD, focus group discussions; IDI, in-depth interviews; PBF, performance-based financing. 
study design and allowed us to remain faithful to protocol and research questions, while remaining open to unexpected or unforeseen findings. We applied analyst triangulation (two researchers independently coded the material), data triangulation (multiple sources of data) and method triangulation (different coding techniques). The final interpretation of findings was discussed among all authors and with selected key informants closely related to PBF implementation in Cameroon.

\section{RESULTS}

Key findings are displayed to represent (1) views and perspectives on $\mathrm{PBF}$, changes and challenges, (2) factors that explain heterogeneity in results across selected PBF indicators and (3) factors that explain heterogeneity in performance across PBF facilities.

\section{Perspectives on PBF}

Providers and managers interviewed held positive views of PBF and the changes it introduced. Many mentioned that PBF 'encourages us', it 'motivates us', it 'improves our situation', it 'helps the facility', it 'makes us work hard', and it 'rewards good work'. The main reasons provided to explain the positive accounts concerned the substantial change in the mentality of health workers and in their attitude towards work. Health workers reported that the requirements of $\mathrm{PBF}$ and the standards and tools defined in the contracts helped them become more rigorous in their work and compelled them to strive for continued, collective improvements-as an interviewee said, $\mathrm{PBF}$ has brought 'the spirit of getting better' (DMO). Others stressed how PBF gave health workers a sense of direction and purpose.

\footnotetext{
"Now they have improved. If you work well you are going to be motivated and it also gives us a sense of direction that is very important (...). PBF has made us change our attitude: it is good to give your clients good services, which PBF can also buy" (Provider, District Hospital).
}

Individual financial incentives played a key role in the narratives of health workers on PBF. Financial incentives for health workers were often referred to simply as 'motivation' (both in English and French) during interviews and were seen as a fundamental positive element of PBF given incentives' role in improving the livelihoods of health workers, and in particular those who had no other formal source of income. Moreover, individual PBF bonuses reduced the need for financial coping strategies, such as parallel sale of drugs.

To a lesser extent, improvements in the work environment (such as improvements in infrastructure and equipment, as well as the possibility to recruit additional personnel using PBF funds), further bolstered positive views. However, it was difficult, and at times impossible for many facilities, to address key structural challenges (eg, availability of running water and electricity) using PBF funds. While such a possibility was foreseen in principle, administrative barriers to autonomous decision-making (see the description of later findings hereafter) coupled with limited funds for low-performing facilities hindered capacity to promote substantial infrastructural changes. Therefore, structural features remained uneven across facilities and districts. Additionally, staff improvements were relatively short-lived because delays in PBF payments negatively affected the retention of those recruited on PBF funds.

Indeed, while the majority of those interviewed agreed that overall PBF had enhanced staff satisfaction and motivation and led to better quality of work, many noted that these positive effects have been diminishing with time, due to challenges related to programme implementation. One key concern was delays in PBF payment, which became starker after the IE period due to a change in the payment processes during the transition from pilot to national programmes. ${ }^{28}$ The prospect of this transition also introduced additional worries, as health workers feared the changes in the price attached to the single indicators that would follow. Workers and managers mentioned how delays demotivated workers, introduced the risk of reverting to illegal income-generating practices and created problems with staff retention. Moreover, without resources, many respondents felt that business plans became an empty exercise, while facilities were deprived of the means to cover expenditures for services provided to the very poor. The enactment of an actual autonomy for facilities was another often-mentioned implementation issue. Most of the providers interviewed agreed that autonomy existed in theory but in practice 'it's not respected', 'it's limited', 'it's only partial', mostly because of the lack of funds (also linked to delays in payment) to realise decisions and make autonomy effective. As one respondent described,

\section{"The main thing is that as long as we don't have funds, we cannot manage (...). Well, we start to have a number of business plans, but then we cannot follow-up on those because we don't have the money for it" (Provider, District Hospital).}

Additionally, respondents reported that the autonomy in financial management envisaged by PBF largely clashed with existing laws regulating financial management at the facility level. Specifically, respondents reported that facilities are normally required to return part of their revenues to the central level. Facilities under PBF should in principle have been exempted from complying with this regulation, allowing them autonomous decision-making in financial management. In practice, however, respondents reported not always being able to work according to the PBF model, due to pressure to comply with pre-existing laws. On many occasions, due to pressure to comply with national regulations, $\mathrm{PBF}$ providers abdicated their autonomy in financial decision-making while on other occasions, they reported acting autonomously, but 'with a degree of fear'.

\section{Heterogeneity in results across indicators}

Our analysis also allows to explore the heterogeneity in results across $\mathrm{PBF}$ indicators, ${ }^{8}$ in particular concerning 
the increase in uptake of vaccination and family planning and the absence of change in assisted deliveries. Two main, interrelated elements emerged that help explain this pattern.

Both providers' and women's narratives highlighted a change over time with providers becoming more proactive in the delivery of some services, in order to increase utilisation and maximise income. Both groups indicated that outreach and sensitisation activities (eg, community and school visits, establishment of outreach posts or family planning sensitisation integrated into antenatal, postnatal or child vaccination visits) had become more common in recent years. Some said,

\footnotetext{
"Especially because it is the 'child completely vaccinated' which are paid for (by PBF), we have to keep doing it, we have to increase our outreach activities" (Provider, District Hospital).

"In fact, yes (there are more children being vaccinated). (...) Now the nurses come to sensitize us, they even knock at our doors, "mami we are to tchouk (give) vaccines ooo"' (woman, South-West region).
}

This change of practice was focused on services, such as family planning and vaccination, which were already free and where an increase in coverage could be obtained via outreach and sensitisation, while other services (such as assisted deliveries) were less of a focus because strategies to increase uptake would have been more difficult to implement, especially given demand-side barriers (assisted deliveries and antenatal visits are charged a fee). Indeed, demand-side barriers emerged as a key factor to influence uptake of certain services, as both providers and women explained,

\footnotetext{
"Those who deliver at home do so because of financial reasons. It is a monetary issue" (Provider, Health Center, South-West region).
}

"I don't know anybody that prefers to deliver at home. But there are some parents that deliver at home because of lack of finance" (woman, North-West region).

Respondents described demand-side barriers to include geographical (distance from the facility) barriers as well as financial ones, related to both direct costs (fees) and indirect costs (transport). Demand-side barriers were not explicitly addressed in the PBF programme and they would have been more difficult to overcome by providers alone. Although a system was in place to ensure and improve access to care for the very poor, this was seen as ineffective by providers, managers and women. Interviews showed that the mechanism was not well known by providers, especially lower cadres in primary facilities. Additionally, its design and the way the very poor were identified varied by region and was described as 'anarchic' by one respondent, who emphasised that identifying the exceptionally poor was difficult in the absence of structured procedures to do so. Finally, delays in the payment of PBF bonuses to facilities made it impossible to recover the costs of care provided for free to the poor.

\section{Heterogeneity in performance between facilities}

We explored the issue of heterogeneity in performance between PBF facilities formulating hypotheses and potential explanations and found that factors influencing facility performance extend across three levels: contextual, facility and individual.

First, contextual factors related to the position of the facility (eg, rural/urban, ease of access and supply, densely populated vs large and sparsely populated area, serving a wealthy or poor or mobile population, competition with other providers and so on), as well as historical factors (length of facility's presence, trust of communities) seemed to influence the performance of the facility. For example, a low performing facility was operating on an abandoned industrial site which had a dwindling and poor population. In those cases, as one of the respondent stressed, it was difficult to achieve high performance, while it was easier to do so in more heavily populated areas:

"The principal reason is the population in the catchment area. The greater the population, the better the performance" (DMO).

While the equity bonus in place should have helped facilities overcome some of the context-related issues, its implementation which was partial and uneven across regions may have contributed to the variation in facilities' performance.

Second, the availability of infrastructure (decent buildings, access to water and electricity and so on), materials and equipment and the presence of qualified staff, predating the introduction of $\mathrm{PBF}$, were often mentioned to explain a facilities' performance and constraints. Many noted that PBF started without considering the level of preparedness of facilities in terms of staff, equipment and infrastructure and this led insufficiently equipped facilities to struggle. As one district manager said,

"When PBF came, they did not put a level ground. They just started, they took health center equal to health center. Whether you have one staff, whether you have twenty staff, whether you have a microscope, whether you have equipment..." (DMO).

Finally, factors related to individual health workers' (and in particular facility in-charges') skills, such as their seniority, leadership, management capacity, entrepreneurial spirit and their understanding of PBF based on PBF-specific training and previous experience in a PBF facility, were reported to have an impact on the facility's performance. Heterogeneity in performance was often explained in relation to the capacity of single managers to make use of the increased, although limited, autonomy granted by the programme, to identify effective changes in practice, by overcoming the fear to make mistakes. As a DMO said,

"(There are) some health facilities in the district that have very sharp leadership and with that sharp leadership they can put in place strategies that will lead to 
better productivity. There are others that their leadership is a bit problematic. We have so many health centers that have nurse aides as chief of center because the state registered nurses are not there. We have centers with one staff" (DMO).

\section{DISCUSSION}

This qualitative study brings together narratives of actors from both the health system's demand and supply side that were affected by the introduction of the PBF pilot programme in Cameroon. The key findings resonate with those from other settings, as they show that overall providers and managers held positive views of PBF because it changed attitudes towards work, bolstered a sense of direction and purpose and rewarded those involved with financial incentives. ${ }^{9} 111315$ 29-31 However, a series of challenges hampered the capacity to produce change to an extent that would have been possible and may explain some of the mixed results found in the IE. A challenge concerned the limits to facility autonomy and the discrepancy between autonomy de jure under PBF and de facto. ${ }^{10}$ Similar to other contexts, ${ }^{9} 10131532$ delays in PBF payments (although starker after the IE period) were a source of frustration and ultimately led to demotivation of health workers and may have had negative effects on the programme's results.

Importantly, this study adds to the existing literature on PBF as the analysis of providers, managers and communities' perspectives builds on a quantitative IE and thus sheds light on the factors explaining the impact of PBF (as found in the IE) and outlining causal pathways to change. Heterogeneity in results across indicators may be explained by the changes in providers' practice (eg, more outreach, greater focus on quality of service provision) that focused on services where a substantial change in coverage could be obtained at a low cost for providers and demand-side barriers were less important. This echoes findings from Benin ${ }^{30}$ and Burundi ${ }^{3}$ and suggests that changes across a wider range of services can only be produced if changes in purchasing structures are accompanied by measures to remove demand-side barriers. Fewer changes were reported in the quality of care (eg, women complained about bad reception and lack of sufficient explanation of family planning's side effects), which is more complex to obtain. This result is in line with the Cameroon $\mathrm{IE}^{8}$ and other studies, ${ }^{733}$ which expectedly found that PBF improved structural elements of quality of service delivery (eg, equipment and drug availability) but not process ones (eg, quality of clinical encounter). Furthermore, our findings indicate that heterogeneity in facility performance was largely attributable to the capacity of single managers to executing leadership skills, making use of the limited resources available and the increased, although constrained, autonomy granted to PBF facilities. Additionally, also in line with prior evidence from Benin, Tanzania and Nigeria, ${ }^{30} 3435$ our analysis confirmed that differences in performance between facilities may be due to factors at contextual, facility and individual levels predating the launch of PBF. This seems to suggest that facilities which were advantaged for what concerns those factors (and therefore likely to be already performing well before the introduction of $\mathrm{PBF}$ ) may have thrived under PBF, while worse-off facilities kept struggling and their performance improved relatively less, if at all. One can also postulate that worse-off facilities are also often the ones caring for the poorest populations; hence, they may face an additional barrier in improving their performance, given the additional expectation to provide care for free to the very poor. This emerging hypothesis warrants further quantitative research in Cameroon and other contexts.

\section{Methodological considerations}

From a methodological perspective, our study adopts a novel approach, which builds on an open dialogue with concerned policymakers and implementers and looks at explaining and exploring meaning behind the effects detected by the quantitative IE. While many studies have previously used qualitative methods to explore issues pertaining to PBF implementation, ${ }^{9} 173234$ they have not, to our knowledge, been explicitly set to explain observed heterogeneity in effects. However, our qualitative study was not planned ex ante as part of a comprehensive mixed-methods study. ${ }^{27}$ This limited our methodological choices in terms of design and data collection and we might have missed out on specific opportunities, such as engaging in a longitudinal design or better integrating quantitative and qualitative data collection and analysis. Furthermore, the delay between the quantitative and the qualitative data collection inevitably affected respondents' recall. While we were interested only in events pertaining to the IE phase, respondents at times struggled to differentiate events having taken place before, during or after the IE (eg, delays in payment, changes in vaccination practices). In addition, in spite of all due precautions we took to this regard (clear semistructured interview guide, trained local interviewers with no direct relation to the $\mathrm{PBF}$ programme, confidential interview setting), we cannot exclude the risk, inherent to all social research, which respondents at times provided socially appropriate answers to fulfil normative expectations.

\section{Policy recommendations}

As PBF is further scaled up in Cameroon and as it continues to garner considerable buy-in from the Ministry of Public Health, this study not only generates policy-relevant knowledge that can be used to inform PBF rollout in coming years in Cameroon but also highlights lessons that are generalisable to PBF in other low-income and middle-income contexts. We advance here a few policy recommendations. First, there is a need to pay more attention and effectively address implementation challenges, such as those causing delays in payment and limiting autonomy, which undercut facilities' capacity to generate change and hinder PBF from functioning at its 
full potential. ${ }^{101732}$ Second, demand-side barriers (such as geographical distance and payments at point of use) remain a powerful constraint in increasing the uptake of certain services. It would be interesting to test whether combining PBF with demand-side incentives, following the example of other countries, such as Burundi where $\mathrm{PBF}$ is implemented in the context of targeted free healthcare $^{5}$ or Malawi where PBF has been coupled with conditional cash transfers, ${ }^{36}$ can produce effective changes on a wider range of indicators. This would also allow investigating whether $\mathrm{PBF}$ has a multiplicative effect when coupled with demand-side interventions as some suggested. ${ }^{5}$ Similarly, in line with what documented in prior studies, ${ }^{4} 37$ offering higher reimbursements for the care of the very poor does not seem to be enough to effectively reach disadvantaged populations and increase care among the very poor. Direct investments in targeting and in demand-side interventions are needed. Third, in order to ensure performance improvements across districts and facilities, a better functioning equity bonus, streamlined across all areas and including the different elements hampering facilities' performance (including size of catchment area, poverty levels as well as remoteness) should be in place and it may be also worthwhile to provide additional resources to facilities at the start of the PBF programme for initial infrastructural and personnel upgrades, since in poorly equipped or otherwise disadvantaged facilities, PBF does not seem to be able to generate change to the extent it does in better-off facilities.

Acknowledgements The authors are grateful to all healthcare providers, district managers, regional and national officers that supported the study, either by participating in the interviews or in the initial planning workshop. The authors are equally grateful to all the women who took part in the FGDs and the individual interviews. Our special thanks goes to the CERASS interviewers who spent time on the field, at times during situation of social unrest, to make the realisation of this study possible. Last, we would like to thank the World Bank staff, in particular Saidou Hamadou and Jean-Claude Taptue Fotso, who untiringly answered all our questions and shared with us all relevant implementation documents, and the Impact Evaluation team, particularly Damien de Walque and Maria Steenland, who patiently accompanied us to build a careful understanding of the quantitative findings on which we built our qualitative work

Contributors MDA and PJR initiated the study and identified the broad research design and methodology. MDA, PJR, SMM and IM were responsible for discussions with the IE and the local teams and for making all specific study design and methodology choices. SMM, MDA and IMC drafted the interview guides. IMC was in charge of training research assistance and coordinating data collection. MPB was in charge of analysis, supported by MDA for purpose of triangulation. MPB and MDA drafted the final manuscript, with contributions from all authors.

Funding This study was financed by the World Bank Health Results Innovation Trust Fund.

Competing interests This study was financed by the Health Results Innovation Trust Fund, managed by the World Bank. The authors report having received personal fees from the World Bank during the conduct of the study, but not for reelaborating findings for the manuscript and writing it. While the last author is staff at the World Bank, all other authors are independent academic researchers and for this study, they were engaged as consultants by the World Bank for various periods of time. The authors were granted full autonomy in making scientific decisions and re-elaborated findings from the study for this publication beyond the framework of their consultancy contract with the World Bank. The World Bank did not interfere with the decision to write this manuscript, its content or the decision to submit it for publication. Hence, the views presented represent those of the authors and can by no means be considered representative of the World Bank and its Directors.

\section{Patient consent Obtained.}

Ethics approval The study obtained ethical clearance from the National Ethical Committee for Research for Human Health of the Ministry of Public Health in Cameroon.

Provenance and peer review Not commissioned; externally peer reviewed.

Data sharing statement Given the sensitive nature of qualitative research and the possibility to identify single respondents (even once names are removed), we are not in the position to make the full transcripts of the interviews available on a public depository. However, we are willing to make data available upon reasonable request. Interested persons should contact the corresponding author.

Open Access This is an Open Access article distributed in accordance with the Creative Commons Attribution Non Commercial (CC BY-NC 4.0) license, which permits others to distribute, remix, adapt, build upon this work non-commercially, and license their derivative works on different terms, provided the original work is properly cited and the use is non-commercial. See: http://creativecommons.org/ licenses/by-nc/4.0/

(C) Article author(s) (or their employer(s) unless otherwise stated in the text of the article) 2018. All rights reserved. No commercial use is permitted unless otherwise expressly granted.

\section{REFERENCES}

1. Fritsche G, Soeters R, Meessen B. Performance-based financing toolkit. Washington, DC: World Bank, 2014

2. Binyaruka P, Patouillard E, Powell-Jackson T, et al. Effect of paying for performance on utilisation, quality, and user costs of health services in Tanzania: a controlled before and after study. PLoS One 2015;10:8.

3. Bonfrer I, Van de Poel E, Van Doorslaer E. The effects of performance incentives on the utilization and quality of maternal and child care in Burundi. Soc Sci Med 2014;123:96-104.

4. Bonfrer I, Soeters R, Van de Poel E, et al. Introduction of performance-based financing in burundi was associated with improvements in care and quality. Health Aff 2014;33:2179-87.

5. Falisse JB, Ndayishimiye J, Kamenyero V, et al. Performance-based financing in the context of selective free health-care: an evaluation of its effects on the use of primary health-care services in Burundi using routine data. Health Policy Plan 2015;30:1251-60.

6. Basinga P, Gertler PJ, Binagwaho A, et al. Effect on maternal and child health services in Rwanda of payment to primary healthcare providers for performance: an impact evaluation. Lancet 2011;377:1421-8.

7. Brenner S, Wilhelm D, Lohmann J, et al. Implementation research to improve quality of maternal and newborn health care, Malawi. Bull World Health Organ 2017;95:491-502.

8. De Walque D, Robyn PJ, Saidou H, et al. Looking into the performance-based financing black box: evidence from an impact evaluation in the health sector in Cameroon. Washington, DC: World Bank, 2017. Policy Research working paper no. WPS 8162, Impact Evaluation series.

9. Ogundeji YK, Jackson C, Sheldon T, et al. Pay for performance in Nigeria: the influence of context and implementation on results. Health Policy Plan 2016;31:955-63.

10. Ssengooba F, McPake B, Palmer N. Why performance-based contracting failed in Uganda - an "open-box" evaluation of a complex health system intervention. Soc Sci Med 2012;75:377-83.

11. Yé M, Diboulo E, Kagoné M, et al. Health worker preferences for performance-based payment schemes in a rural health district in Burkina Faso. Glob Health Action 2016;9:1-12.

12. Paul E, Sossouhounto N, Eclou DS. Local stakeholders' perceptions about the introduction of performance-based financing in Benin: a case study in two health districts. Int $J$ Health Policy Manag 2014;3:207-14.

13. Bertone MP, Lagarde M, Witter S. Performance-based financing in the context of the complex remuneration of health workers: findings from a mixed-method study in rural Sierra Leone. BMC Health Serv Res 2016;16:286.

14. Shen GC, Nguyen HT, Das A, et al. Incentives to change: effects of performance-based financing on health workers in Zambia. Hum Resour Health 2017;15:20.

15. Bhatnagar A, George AS. Motivating health workers up to a limit: partial effects of performance-based financing on working environments in Nigeria. Health Policy Plan 2016;31:868-77.

16. Wilhelm DJ, Brenner S, Muula AS, et al. A qualitative study assessing the acceptability and adoption of implementing a results 
based financing intervention to improve maternal and neonatal health in Malawi. BMC Health Serv Res 2016;16:398.

17. Ridde V, Yaogo M, Zongo S, et al. Twelve months of implementation of health care performance-based financing in Burkina Faso: a qualitative multiple case study. Int J Health Plann Manage 2017;15:1.

18. McMahon SA, Brenner S, Lohmann J, et al. Evaluating complex health financing interventions: using mixed methods to inform further implementation of a novel PBI intervention in rural Malawi. BMC Health Serv Res 2016;16:414.

19. Renmans D, Holvoet N, Orach CG, et al. Opening the 'black box' of performance-based financing in low- and lower middleincome countries: a review of the literature. Health Policy Plan 2016;31:1297-309.

20. UNDP. Cameroon Human Development Indicators. http://hdr.undp. org/en/countries/profiles/CMR (accessed 25 Jul 2017).

21. Victora CG, Requejo JH, Barros AJ, et al. Countdown to 2015: a decade of tracking progress for maternal, newborn, and child survival. Lancet 2016;387:2049-59.

22. Institut National de la Statistique. Demographic and health survey, Cameroon. Yaoundé \& Maryland, USA: Institut National de la Statistique \& CellC, 2011.

23. UNAIDS. Cameroon HIV and AIDS estimates. 2015 www.unaids.org/ en/regionscountries/countries/cameroon (accessed 17 July 2017).

24. World Bank. Combined Project Information Documents / Integrated Safeguards Data Sheet (Pid/Isds) Appraisal Stage). Washington, DC: World Bank, 2016. Health System Performance Project (P156679) Report No: PIDISDSA16709.

25. Sieleunou I, Turcotte-Tremblay AM, Fotso JT, et al. Setting performance-based financing in the health sector agenda: a case study in Cameroon. Global Health 2017;13:52.

26. AEDES-IRESCO. Performance based financing implementation procedures. Manual for the North-West region of Cameroon. Bamenda, Cameroon: AEDES-IRESCO, 2012.

27. Creswell J, Clark P V. Designing and conducting mixed methods research. Thousand Oaks, CA: Sage Publications, 2007.

28. Sieleunou I, Turcotte-Tremblay A-M, Yumo HA, et al. Transferring the purchasing role from international to national organizations during the scale-up phase of performance-based financing in Cameroon. Health Syst Reform 2017;3:91-104.

29. Bertone MP, Meessen B. Studying the link between institutions and health system performance: a framework and an illustration with the analysis of two performance-based financing schemes in Burundi. Health Policy Plan 2013;28:847-57.

30. Paul E, Lamine Dramé M, Kashala JP, et al. Performance-based financing to strengthen the health system in Benin: challenging the mainstream approach. Int J Health Policy Manag 2017;7:35-47.

31. Lohmann J, Wilhelm D, Kambala C, et al. 'The money can be a motivator, to me a little, but mostly PBF just helps me to do better in my job.' An exploration of the motivational mechanisms of performance-based financing for health workers in Malawi. Health Policy Plan 2018;33:183-91.

32. Antony M, Bertone MP, Barthes O. Exploring implementation practices in results-based financing: the case of the verification in Benin. BMC Health Serv Res 2017;17:204.

33. Wulifan JK, Brenner $\mathrm{S}$, Jahn $\mathrm{A}$, et al. A scoping review on determinants of unmet need for family planning among women of reproductive age in low and middle income countries. BMC Womens Health 2016;16:2.

34. Olafsdottir AE, Mayumana I, Mashasi I, et al. Pay for performance: an analysis of the context of implementation in a pilot project in Tanzania. BMC Health Serv Res 2014;14:392.

35. Mabuchi S, Sesan T, Bennett SC. Pathways to high and low performance: factors differentiating primary care facilities under performance-based financing in Nigeria. Health Policy Plan 2018;33:41-58.

36. Brenner S, Muula AS, Robyn PJ, et al. Design of an impact evaluation using a mixed methods model--an explanatory assessment of the effects of results-based financing mechanisms on maternal healthcare services in Malawi. BMC Health Serv Res 2014;14:180.

37. Flink IJ, Ziebe R, Vagaï D, et al. Targeting the poorest in a performance-based financing programme in northern Cameroon. Health Policy Plan 2016;31:767-76. 